\title{
LA CIUDAD DESDE EL AIRE EN LAS PANTALLAS. ESPECTADOR Y TRANSEÚNTE
}

Jorge Gorostiza López

Real Academia Canaria de Bellas Artes

ORCID: https://orcid.org/0000-0002-0547-610X

\section{RESUMEN}

La vista del paisaje urbano desde lo alto ha fascinado a los seres humanos, una mirada diferente a otras y que modifica la percepción de la ciudad. El cine desde sus inicios ha empleado esa mirada aérea urbana, mostrando las ciudades directamente desde aeronaves y también como fondo de otros artefactos voladores. Según donde se sitúe la cámara en esas aeronaves, cambia el punto de vista, que puede ser frontal, trasero, lateral e inferior, en cuanto a lo observado desde las alturas, se han elegido inicios de películas filmadas en Madrid. En la actualidad hay otra mirada a la ciudad mediatizada por los programas informáticos La representación aérea y en movimiento de las ciudades, implica un nuevo modo de pensar y experimentar el paisaje urbano, que provoca un cambio significativo en los espectadores y transeúntes.

Palabras clave: cine, ciudad, aviación, visión, Madrid

\section{ABSTRACT}

Aerial views of the urban landscape have long been a source of fascination, providing an alternative take of the city and altering perceptions of it. Cinema has used the overhead urban shot since its inception, showing cities directly from aircraft and also as the backdrop to other flying machines. The point of view (front, rear, side and below) changes depending on where the camera is placed on the aircraft. As regards what is seen from above, the openings of films shot in Madrid have been chosen. There now exists another view of the city that has been obstructed by computer programs. Representation of cities from the air and in motion implies a new way of thinking and of experiencing the urban landscape, which brings about a significant change in audiences and passers-by.

Keywords: cinema, city, aviation, vision, Madrid

«La contemplación de la Tierra desde el aire conduce a la meditación» Le Corbusier $^{1}$

El espectador permanece inmóvil observando el espectáculo, mientras el transeúnte se mueve recorriendo un lugar, parece que estas actitudes serían contradictorias, pero hay un espacio donde ambas coinciden, dentro de un vehículo en movimiento. En un medio de locomoción el espectador puede estar sentado quieto, mirando a través de una ventanilla, al mismo tiempo que está desplazándose, sin realizar esfuerzos, esta inmovilidad le permite centrarse en el acto de mirar hacia el exterior, observando cómo el entorno que le rodea va cambiando mientras el vehículo se mueve.

El viajero tanto en un ferrocarril, como en un automóvil, está sobre el terreno, sin que se modifique la altura de su punto de vista, sin embargo, 
en una aeronave ese punto de vista va modificándose según se eleve o descienda su trayectoria en el espacio. La visión aérea global, es la que abarca más territorio en un mismo instante y además la que permite una mayor objetividad, permitiéndole tener menos interferencias, al no involucrarse físicamente con lo que está viendo, debido a la distancia del observador establecida por la altura de la aeronave.

Los seres humanos siempre estuvieron interesados en la visión desde arriba, que abarcara una gran extensión de terreno, los mapas y planos no solo servían para conocer cómo era ese terreno y para recorrerlo sin correr riesgos, sino además para conquistarlo o defenderlo. La representación de las ciudades también fue pronto crucial no solo para para conocer su morfología, sino además para atraer a los viajeros dando a conocer sus peculiaridades urbanas y monumentos más notables.

Este interés por el paisaje urbano visto desde lo alto, también produjo representaciones pictóricas, como la vista de Nápoles en la Tavola Strozzi de 1472 y además se emplearon instrumentos como los panoramas del siglo dieciocho, en los que incluso se repetían vistas de una misma ciudad desde lugares diferentes, como las que pintó Robert Barker de Constantinopla desde las torres de Gálata y la Doncella y de Edimburgo desde la colina Calton y la torre de la catedral. Desde entonces hasta la actualidad numerosos artistas se han interesado por las vistas aéreas, pudiéndose mencionar el Manifiesto de la Aeropintura Futurista de 1929 e ilustraciones como las de Eduardo García Benito para el folleto Dans le ciel de la patrie, escrito por Jean Cocteau en 1918, para la sociedad Spad, constructora de los célebres biplanos franceses, así como las fotografías aéreas de ciudades publicadas en el libro de Kazimir Malévich El Mundo No Objetivo de 1927.

Se debe señalar que las vistas urbanas desde aeroplanos, no solo le interesaban a los artistas, sino también a la población, estando ligada, como el cine, a las ferias donde había primero globos y después aeroplanos a los que se podía subir pagando una cantidad de dinero, además se desarrollaron simulacros, como la atracción que se instaló en el Tibidabo de Barcelona en 1928 y aun funcionamiento, que consiste en una réplica del primer avión que había realizado el trayecto de Barcelona a Madrid el año anterior y cuya única función es dar vueltas alrededor de una torre, sujeto por una grúa, para que sus pasajeros vean la ciudad desde lo alto.

\section{La mirada aérea}

La inmovilidad del espectador -transeúnte le permite centrarse en el acto de mirar hacia lo que le rodea, esta mirada es diferente a otras y por supuesto modifica la percepción de la ciudad que se tenía hasta entonces. En 1912, Marinetti escribió en su Manifiesto técnico de la literatura futurista: "observando los objetos desde un nuevo punto de vista. ya no de cara o de espalda, sino de pico, o sea de escorzo, he podido romper las viejas trabas lógicas y los hilos de plomo de la comprensión antigua»², confirmando que el lugar desde donde se mira,en este caso la vista aérea, cambia la visión e incluso llega a producir una nueva forma de entender la realidad.

Ese mismo año Picasso pintó el bodegón cubista Notre avenir est dans l'air y como ha explicado Juan José Lahuerta ese porvenir está «en el poder de la vista de pájaro, en el poder de separarse, de sobrevolar con una Obra todas las contradicciones» ${ }^{3}$ y añade refiriéndose a Le Corbusier,que este mensaje «unos lo entendieron bien» ${ }^{4}$.

Efectivamente, este arquitecto ya había mencionado a los aviones en la revista L'Esprit Nouveau y en su libro Vers une architecture de 1923, que recoge artículos de esa revista, manifestando que el avión es una «máquina de volar» ${ }^{5}$ como la casa debe ser una "máquina de habitar» ${ }^{6}$, más de una década después, en 1935, escribió el libro Aircraft en el que volvió a constatar su admiración por los propios aeroplanos, así como por lo que se ve desde ellos, indicando cómo el vuelo facilita la meditación y una forma distinta de pensar y además para el ser humano «ahora el ojo ve en sustancia lo que antes su mente solo podía concebir subjetivamente. Una nueva función añadida a nuestros sentidos. Un nuevo patrón de medida. Una nueva base para la sensibilidad ${ }^{7}$, gracias a que «el aeroplano, en el cielo, transporta nuestros corazones por encima de todo lo mediocre. El avión nos ha dado la mirada a vista de pájaro. Cuando los ojos ven claramente, la mente puede 
decidir con claridad»»., el punto de vista aéreo implica una nueva mirada y una forma de pensar distinta que debería servir para modificar los objetos, así como las ciudades.

\section{En movimiento}

«El agonizante siglo XIX nos lega dos nuevas máquinas. Ambas nacen casi en la misma fecha, casi en el mismo lugar, se lanzan simultáneamente por el mundo, cubren los continentes. Pasan de las manos de los pioneros a las de los explotadores» ${ }^{9}$, así comienza el primer capitulo, «El cine, el avión», de El cine o el hombre imaginario, escrito por Edgar Morin en 1956, en el que se constata la relación entre la imagen en movimiento y la aviación desde sus inicios.

Pero no solo existe esa relación seminal entre la aeronave y el cinematógrafo, también hay otra más profunda expresada por Nam June Paik en la paráfrasis: «Le cinéma ce n'est pas je vois, c'est je vole»10 (El cine no es qué veo, es qué vuelo) de modo que lo mostrado en las pantallas es más que una vista, sino es más un acto de sobrevolar lo real.

Dos años después de la proyección pública efectuada por lo hermanos Lumière en el Grand Café de París, en 1897, uno de sus operadores rodó Panorama pris d'un ballon captif, en ella se situó la cámara en un globo cautivo, verticalmente encuadrando el terreno, y se ve cómo se va elevando sobre una explana, al mismo tiempo que se desplaza de lado hasta volar sobre las cubierta de tejas de un edificio. Ese movimiento ascendente vertical, que fue uno de los primeros que se pudieron ver en las pantallas, solo pudo volver a mostrase muchos años después, cuando se colocaron cámaras en helicópteros.

Esta visión urbana desde un globo aerostático no era nueva, desde que surgió la fotografía ya se habían colocado cámaras en aeronaves, obteniéndose vistas desde el aire de ciudades como París, a través de las fotos que hizo Nadar en 1858, Photographie aérostatique de Paris, y 1868, L'Arc de Triomphe et les grans boulevards de Paris vus d'un ballon.

También se filmaron otras vistas aéreas de ciudades usando globos, como Bird's-Eye View of San Francisco, From a Ballon de la compañía de Edison, filmada a principios de 1902, con una duración aproximada de tres minutos, está compuesta por cuatro planos, viéndose como la ciudad se va alejando y en el último plano acercándose, el movimiento ascendente parece más lento que el de la película de los Lumière, porque no empleó el punto de vista cenital, sino el oblicuo encuadrando hacia el horizonte.

El interés por las vistas aéreas influyó incluso en el modo como se mostraban las proyecciones, en 1900, Raoul Grimoin-Sanson presentó su Cinéorama en la Exposición Universal de París, en este espectáculo el público entraba en un edificio, ascendía por una escalera y llegaba a lo que simulaba ser una gran barquilla de un globo aerostático, situado en el interior de un cilindro de cien metros de diámetro, se apagaba la luz y comenzaba la proyección de diez películas sincronizadas sobre las paredes de ese cilindro, viéndose la ascensión desde un globo real que partía de París, seguida de imágenes aéreas de Niza, Biarritz, Túnez, Southampton y finalmente una corrida de toros en Barcelona, este efecto se lograba gracias a diez proyectores que estaban en una cabina cilíndrica, debajo de los espectadores, desgraciadamente Grimoin-Sasoin no había previsto el enorme calor generado por estos aparatos, que en la primera exhibición provocó el desmayo de los proyeccionistas; por lo que el espectáculo no volvió a repetirse, pero como he escrito, será recurrente «la idea, inspirada en los panoramas que todavía existen en varias partes del mundo, de eliminar el límite entre realidad y ficción»"

Los cineastas se dieron cuenta pronto de los problemas que se producían al rodar desde aeronaves, en 1911, André Prothin escribió sobre sus filmaciones desde un avión, afirmando que para poder rodar el paisaje urbano de Reims a mil cien metros de altitud, era indispensable tener un tiempo despejado «porque vista desde arriba, una ciudad importante no es más que un océano de techos cuyo color gris es casi uniforme» 12; desde el aire y con el cielo nublado, la urbe se convierte en una superficie sin relieve y grisácea, como el mar, que no merece ser filmada, porque no se parece a una ciudad al no distinguirse sus edificaciones, ni sus monumentos. 
Los problemas no solo los causaban el tiempo atmosférico y la escasa iluminación, en una nota anónima publicada en 1920 en la revista Moving Picture World: se indicaba: «las vistas desde aviones no son nuevas, pero la rápida velocidad del avión ha tenido poco valor para fotografiar escenas dramáticas reales, aparte de comedias y películas de suspense o material a vista de pájaro. No puede reducirse a la velocidad de la acción normal sobre el terreno y por eso tiene poco valor para obtener un nuevo ángulo para fotografiar escenas directamente ${ }^{13}$, efectivamente, a causa de su característica esencial, su velocidad de desplazamiento, no servía para seguir la acción ficticia de los personajes desarrollada sobre el terreno, pero era ideal para vistas de pájaro y por ello para mostrar panorámicas sobre ciudades en movimiento.

Esta relación con la ficción no impide que la visión desde lo alto se convierta en una atracción en sí misma, Teresa Castro advierte sobre la «aparentemente paradójica correlación entre descripción y espectáculo en las vistas aéreas urbanas cinemáticas» ${ }^{14} \mathrm{y}$ añade «no solo mostrando, desvelando y retratando (es decir. describiendo) sino también creando sensaciones visuales y corpóreas (es decir representando el mundo espectacular) ${ }^{15}$, esta correlación permite que esas vistas sean cruciales para la narración cinematográfica dotándola de un significado distinto al de otras visiones.

Lo más común es que las ciudades hayan sido mostradas en las pantallas directamente desde vehículos aéreos, pero también es posible que haya elementos, casi siempre otra aeronave, entre el punto de vista y el paisaje urbano que se ve como fondo, hay cientos de estos planos en secuencias de muchas películas, pero son notables dos ejemplos de la misma época. El primero es el inicio de El triunfo de la voluntad (Triumph des Willens, Leni Riefenstahl, 1934), viéndose un trimotor Junkers Ju 52 con la matrícula D-2600 y detrás Nüremberg, en algunos planos también se muestra esa ciudad desde arriba y la sombra del avión, no se explica quién está en su interior, hasta que el aeroplano aterriza y desciende Adolf Hitler, en aquella época en Alemania se sabía que esa matrícula correspondía al avión particular del Führer y no se tendría la sorpresa que se tiene ahora al verlo rodeado de otros jerarcas nazis uniformados, esta secuencia tiene un significado más profundo y terrible, ya que empieza, como ha escrito Krakauer, con «bancos de maravillosas nubes, reencarnación del padre Odín a quien los antiguos arios oían atronar con sus huestes sobre la selvas vírgenes» ${ }^{16}$, el dictador, protegido por ese deidad o siendo su propia reencarnación, primero ve y controla a los ciudadanos desde arriba, y después desciende del cielo, como si fuera otro dios, el único vivo, que baja a la tierra para salvar a su pueblo acometiendo una tarea providencial.

El otro ejemplo es el último número musical de Volando hacia Rio de Janeiro (Flying down to Rio, Thornton Freeland, 1933), en el que como las autoridades han prohibido que haya actuaciones musicales en la inauguración de un hotel, para evitar la ruina de su propietario, se decide realizar un gran espectáculo en el aire amarrando sobre las alas de once aeroplanos -entre ellos un Faichild Fc-1, un Douglas M-1 y un Lockheed Vega-, a unas bailarinas que durante el vuelo se mueven rítmicamente al son de la música, llegando incluso a dar saltos de un trapecio a otro colgados del ala inferior de un biplano, hasta que una cae y providencialmente es recogida por un monoplano que vuela por debajo; mientras ellas se mueven, detrás de los aviones puede verse el paisaje urbano de Río de Janeiro, evidentemente gracias a un efecto especial denominado retroproyección, se supone que este gran y peligroso espectáculo está siendo apreciado por los ciudadanos desde el terreno, pero este punto de vista es imposible, ya que las bailarinas estarían ocultas por la parte inferior de las alas, aunque es cierto que en esos años se hacían acrobacias sobre aviones en vuelo, las que se muestran en esta película solo podrían ser vistas en toda su plenitud desde otro aeroplano o en las pantallas tras haber sido filmadas.

En el primer ejemplo se busca la veracidad propia del documental, incluso en una película tan tendenciosa y manipulada como esta, mostrando los edificios históricos y monumentos de una ciudad concreta, de Nüremberg; en el segundo, la ciudad podría ser cualquiera, no teniendo importancia frente a la coreografía que conlleva la fantasía desenfrenada del musical. 
También hay otros dos ejemplos, esta vez del mismo año y de la misma capital, de Madrid, y además en ambos se empleó el mismo plano de un Douglas DC-4 sobrevolando la ciudad, en Vuelo 971 (Rafael J. Salvia, 1953), un viajero le dice a una chica: "Madrid queda bonito desde aquí arriba ¿Verdad? Se ve todo menos los baches», en el segundo, Aeropuerto (Luis Lucia, 1953), hay una voz en over que dice «desde el avión las ciudades ofrecen su plano en el que usted podrá situar fácilmente la iglesia donde contrajo matrimonio, la casa de tía Margarita o el Museo de Prado sin necesidad de preguntar a un guardia», en ambos ejemplos se hace hincapié en el conocimiento que otorga la visión aérea y se bromea con su correspondencia con la ciudad vista desde el terreno. En Aeropuerto hay un plano desde dentro de la cabina de un avión en el que se ve la ciudad tapada en la izquierda del encuadre por una parte del ala, mostrando el paseo de Recoletos, la calle de Alcalá y la Gran Vía, interrumpiéndose justo antes de que se vea la Plaza de España, es curioso que no se lleguen a mostrar el monumento a la Cibeles en el inicio del plano, ni los edificios España y Torre de Madrid, en su final; la elección de lo que se muestra, de los lugares de la ciudad, es muy importante, como se verá en los próximos apartados.

\section{El punto de vista}

Invierno de 1912, Frank Coffyn se sienta en el sillín de un aeroplano Wright modelo $B$, al que le han colocado flotadores, arranca el motor y aunque hay bloques de hielo flotando en el río Hudson, los puede esquivar y comienza su vuelo, no solo es una de las primeras veces que se despega desde el agua, también hay otra novedad importante, a su lado, entre los dos asientos, han montado una cámara cinematográfica, enfocando hacia la parte delantera del avión; Coffyn comienza volando hacia la Estatua de la Libertad y la isla de Ellis, luego pasa por la estructura cilíndrica de Fort Jay, una prisión militar situada en la isla Governor, vuela por encima de los puentes de Brooklyn y Manhattan, da la vuelta entre los dos y antes de regresar, pasa cerca del Battery Park, en el extremo sur de Manhattan, para terminar amerizando en el río; todo su trayecto lo hace volando sobre el río, posiblemente por problemas técnicos debidos a la baja altura a la que entonces volaban los aviones, por lo que no llegan a mostrase rascacielos, que son una de las visiones más típicas de Nueva York.

Los espectadores ya habían visto la tierra desde arriba en el vuelo que realizó Wilbur Wright en Italia en 1909, pero tres años después pudieron ver, quizás por primera vez, una ciudad desde un aeroplano, sin tener que correr el riesgo de volar en él, sino sentados en sus butacas dentro de un local, así la hazaña no solo quedaría en la memoria de quienes la vivieron en su momento, sino registrada para la historia, gracias a la imagen en movimiento, repitiéndose desde entonces las vistas de monumentos neoyorquinos como la estatua de la Libertad y el puente de Brooklyn. Al colocar la cámara al lado del piloto y con su objetivo hacia el frente, la visión de los espectadores es similar a la del aviador, como si fuera un plano subjetivo de alguien sentado a su lado.

Este punto de vista no es habitual, aunque se ha repetido en películas como 27 horas (Montxo Armendáriz, 1986), cuyo plano inicial comienza encuadrando la ciudad de San Sebastián desde lejos mientras amanece, la cámara se va acercando desde el mar a la playa de La Concha, terminando en un plano de un reloj que marca las siete en punto, indicando inequívocamente el lugar y el momento en que va a comenzar la acción.

Esta visión frontal de la ciudades se empleó en cuadros como Incuneandosi nell'abitato (Acuñándose en lo habitado), también conocido por In tuffo sulla città (Sumergirse en la ciudad), pintado por Tullio Crali en 1939, en el que se ven los edificios de una gran ciudad en un picado que parece irrecuperable, desde dentro de la carlinga de un avión, como si el espectador estuviera sentado detrás del piloto; en el primer título el avión entra en cuña, abriendo un hueco a la fuerza en la población y al mismo tiempo convirtiéndose en un objeto extraño entre ellos, en el segundo, la urbe es un océano, como el mencionado por Prothin, donde el piloto y el espectador van a zambullirse.

El cuadro de Crali tiene como antecedente las fotografías hechas a principios de los años treinta por Filippo Masoero: Scendendo su San Pietro y Aeroveduta della basilica di S. Maria Maggiore in Roma, en las que se ven ambas basílicas desde el aire y logrando un efecto dinámico que simula 
el movimiento descendiente del aeroplano y el espectador al mover la cámara, desenfocándose los márgenes de la imagen,

Otro punto de vista aún menos frecuente es el trasero, cuando la cámara se coloca en la cola mostrando como el paisaje urbano, las nubes o el terreno se van alejando del espectador.

Lo más común es que la ciudad se encuadre desde el lateral de una aeronave, como ha sucedido en numerosas películas, entre ellas, todas las españolas que se mencionarán en el siguiente aparado. Estos dos tipos de vistas, la frontal y la lateral, han sido denominadas «imágenes oblicuas» por Mark Dorrian, con el «ojo dirigido a la vez hacia abajo y lateralmente ${ }^{17}$. Unas imágenes también empleadas en muchos cuadros, entre ellos, Avions fantaisistes pintado por André Devambez en 1914 y los del pintor Richard Caline, quien durante la Primera Guerra Mundial se alistó en la Royal Air Force volando como observador y ametrallador, trasero, pintando en 1918 ciudades destruidas del frente occidental como Ypres, Lens y Bapaume, y el año siguiente otras del oriente próximo como Bagdad, Damasco y Jerusalén; también se han de mencionar las visiones aéreas de la torre Eifffel realizadas por Robert Delaunay como Tour Eiffel et Jardin du Champs de Mars de1922 y otros tres cuadros titulados Tour Eiffel, pintados ese mismo año, en 1924 y en 1926, Sergei M. Eisenstein menciona uno de ellos en su artículo «Laocoonte», relacionándolo con el montaje cinematográfico ${ }^{18}$.

Además de estos puntos de vista, frontal y lateral, hay otro inferior, colocando la cámara debajo de la aeronave y encuadrando la ciudad directamente desde arriba en un eje perpendicular al plano del terreno. Dorrian lo denomina «vertical» y según él «surge históricamente como una forma que es, en oposición a los valores de la visión oblicua, no estética, no aurática, instrumental, desencantada y técnica, en virtud de su mirada directamente hacia abajo sobre el suelo» ${ }^{19}$. Recuérdese que este punto de vista cenital es el de las ortofotografías que se empleaban para dibujar, restituir es el término técnico empleado para esta acción, mapas y planos topográficos. Antes se mencionaba al pintor Richard Carline y también empleó este punto de vista para su cuadro
An Impression of Lens, France, Seen from an Aeroplane The Anglo-German Front Line de 1918.

Philippe Dubois ha escrito sobre este punto de vista, considerando al «cielo y la tierra como campo y como contracampo, estableciendo un efecto de bucle de ficción o cierre de Todo (lo que se llama precisamente "el universo") a partir de lo que puede aparecer como sus dos caras simétricas entre las cuales (en el interior de las cuales) estamos atrapados. Lo que, a partir de este bucle de campo/contracampo se excluye la figura del Horizonte, el horizonte como bisagra articulatoria, como línea de razón del paisaje, como sutura y como conexión entre tierra y cielo» ${ }^{20}$. Dubois emplea términos cinematográficos para explicar este tipo de vistas, como si se tratara de una secuencia en la que hubiera un diálogo entre varias personas situadas unas enfrente de otras, pero relacionándolo con el plano de tierra inferior y un plano virtual superior que sería el aéreo.

Antes ya se ha hablado de la película realizada por el operador de los Lumière, usando este punto de vista vertical, unos años más tarde se repitió en A propósito de Niza (À propos de Nice, Jean Vigo, 1930), que comienza con tres planos aéreos de la ciudad y un cuarto tras una secuencia de animación y una playa; en el primero, el avión gira sobre el puerto, mostrándolo todos sus mueles; en el segundo, va del este hacia el oeste, sobrevolando el jardín Alberto Primero, la avenida de Verdún y el paseo de los Ingleses; en el tercero el recorrido va de noreste a sudoeste, siguiendo la playa y el paseo antes mencionado, viéndose la calle Isadora Duncan y la avenida de Bellet; en el cuarto se sigue la misma dirección que en el tercero viéndose también el paseo y la playa, y yendo desde la calle Cronstadt a la Honoré Sauvan; estos tres últimos recorridos son lineales y abarcan casi la misma distancia, aproximadamente quinientos metros, pero lo significativo es que no siguen un orden lógico, ya que el primero y el segundo están colindantes y en la misma dirección, pero tras ellos tenía que haberse visto el cuarto, al estar situado antes que el tercero. Los cineastas emplean unas imágenes casi abstractas y además crean un paisaje urbano distinto al real, porque ya no es importante sorprender al espectador con la propia vista cenital, sino darle relevancia a lo que se muestra. 


\section{Lo observado}

Como he escrito, las poblaciones «se ven desde un punto de vista celestial equiparando al espectador con un demiurgo que todo lo ve y todo lo sabe, una visión poco habitual para la mayoría de los espectadores, y que gracias a la altura de la cámara y su distancia hasta el suelo, sirve para comprobar la enorme extensión de las metrópolis y por tanto su complejidad, logrando además homogeneizar la morfología de las ciudades, llegando a compararlas con la naturaleza, con junglas llenas de personas con vidas y problemas muy diversos ${ }^{21}$.

Al ser imposible estudiar todos los cientos de paisajes urbanos que se han mostrado desde el aire en las pantallas, se han tomado solo comienzos de películas españolas rodadas en Madrid. Una de las primeras cronológicamente es iViva Madrid que es mi pueblo! (Fernando Delgado, 1928), que comienza viéndose un globo terráqueo flotando entre nubes ${ }^{22}$, pasa a un mapa de España, después hay un inserto de la provincia de Madrid y un dedo femenino señala su capital; el siguiente plano es el aéreo en el que se sobrevuela la Plaza de Cibeles, se sigue por Alcalá y por último sobre la Gran Vía, el recorrido va desde lo general, el planeta, a lo concreto, el mapa con la provincia de Madrid, y después de lo tradicional, la estatua de la Cibeles, a lo moderno, la Gran Vía, cuyo cuarto y último tramo se finalizaría el año siguiente al estreno de la película.

Un recorrido parecido, pero en sentido inverso y dirección perpendicular, se hizo muchos años después en Trío de damas (Pedro Lazaga, 1960) en ella el vuelo sigue el Paseo de Recoletos hasta llegar a Cibeles y entonces, para remarcar la importancia del monumento, se gira varias sobre él para mostrar todo su contorno.

Otro trayecto aéreo se realiza en Buenos días condesita (Luis César Amadori, 1967) que comienza con una panorámica sobre el mapa de Madrid de Pedro Teixeira de 1656, hasta que la cámara hace un zoom sobre la Plaza Mayor, el siguiente plano es de esa plaza desde el aire, hay un giro sobre ella y se vuela hacia el sur por encima de la calle de los Estudios, se pasa sobre la Plaza de Cascorro y la calle Ribera de Curtidores, y a continuación hay un plano desde el nivel de la calle de El Rastro, donde la protagonista, co- nocida por la Condesita, trabaja en un puesto de discos; el plano de Teixeira le da un aspecto de abolengo y nobleza, relacionándolo con el apodo de la protagonista, mientras que las vistas aéreas enlazan directamente con la realidad de un Madrid popular.

Los ámbitos que se muestran en estos planos aéreos iniciales no tienen por qué ser lugares turísticos o emblemáticos, Me enveneno de azules (Francisco Regueiro, 1969) comienza con una vista general de Madrid, sin que sepa muy bien cuál es la zona que se está viendo, hasta que se puede distinguir la trasera del Ministerio del Aire y a continuación el Arco de la Victoria en Moncloa en la lejanía. Otro ejemplo es Una gota de sangre para morir amando (Eloy de la Iglesia, 1973) en la que en un solo plano se sobrevuelan los alrededores del Hospital Universitario La Paz, llegando desde el sur hasta dar una vuelta sobre un edificio en aquel entonces aislado entre solares, casi como un inquietante monstruo varado en una tierra baldía, lo que es adecuado en una película que no se sabe muy bien si sucede en un futuro distópico o en la España de aquel momento.

Sin embargo, no es habitual que en los principios de las películas haya un solo plano aéreo, como en las antes mencionadas, sino varios consecutivos, una de las que incluye en su inicio mayor cantidad de estos planos y más significativos es Las chicas de la Cruz Roja (Rafael J. Salvia, 1958), que comienza con la Puerta de Alcalá, para ir pasando por la Plaza de Cibeles, Edificio España y Torre de Madrid, Gran Vía, Plaza del Callao, estadio Santiago Bernabeu, hipódromo de la Zarzuela, Ministerio del Aire, Palacio de Oriente, Plaza de Ramón y Cajal en la Ciudad Universitaria, Plaza de España, estanque de El Retiro, estadio Santiago Bernabeu de nuevo, la Ciudad Universitaria otra vez pero con la Escuela Técnica Superior de Ingenieros Industriales delante y al fondo el actual Colegio Mayor Guadalupe, Plaza de Neptuno, la Castellana, Plaza del Callao y por último de nuevo la Puerta de Alcalá, como puede observarse (fig. 1), el recorrido no sigue un orden lógico enlazando lugares cercanos, sino que es aleatorio, alternando monumentos conocidos con espacios para el espectáculo, como el hipódromo y el estadio, e incluso repitiendo lugares, 


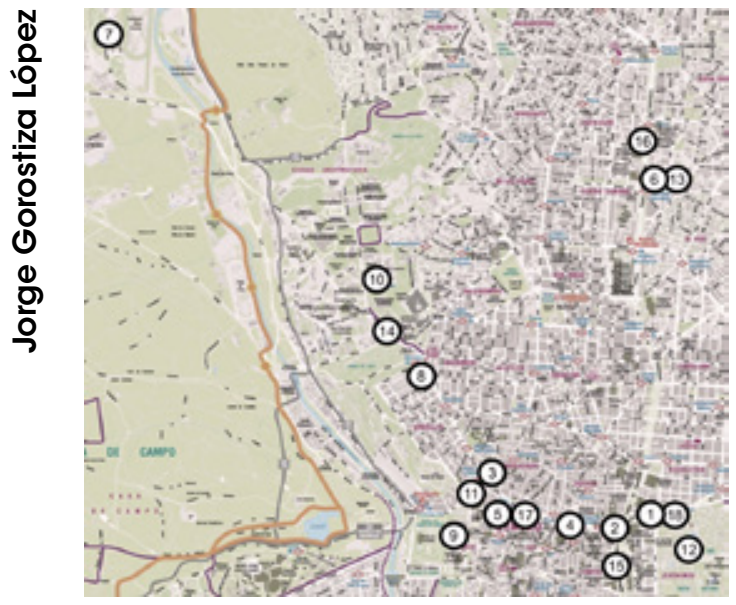

Fig. 1. Lugares de rodaje Las chicas de la Cruz Roja. Fuente: Jorge Gorostiza

como este último, la plaza del Callao y la Puerta de Alcalá que abre y cierra la secuencia.

En Los palomos (Fernando Fernán-Gómez, 1964) se ven el Ministerio del Aire y la Plaza de España, mientras nieva sobre Madrid, en este caso no sólo se indica la ciudad, sino que además se aporta el dato de la estación del año; los edificios España y Torre de Madrid, situados en la plaza mencionada, eran los más altos de nuestro país en esa época y símbolos de la modernidad,

Unos "rascacielos" que también se ven desde el aire en En septiembre (Jaime de Armiñán, 1982), en la que además se muestran los Nuevos Ministerios y la zona de Azca, siguiendo el recorrido del Paseo de la Castellana, otro símbolo de lo moderno en la capital, hasta llegar a la esquina de las calles Pinar y López de Hoyos donde se supone que, en un palacete de cuatro plantas, está el colegio donde han estudiado los protagonistas y que va a ser demolido para edificar un edificio de muchas plantas, aunque hoy aun siga en pie.

La joven casada (Mario Camus, 1975) comienza viéndose desde el aire la estación de Chamartín, después el Parque de El Retiro y por último, la urbanización de bloques de viviendas plurifamiliares donde vive el matrimonio que protagoniza la película, es lógico que empiece con la estación porque es uno de los accesos a la ciudad, pero también por donde se sale de ella y el tren el

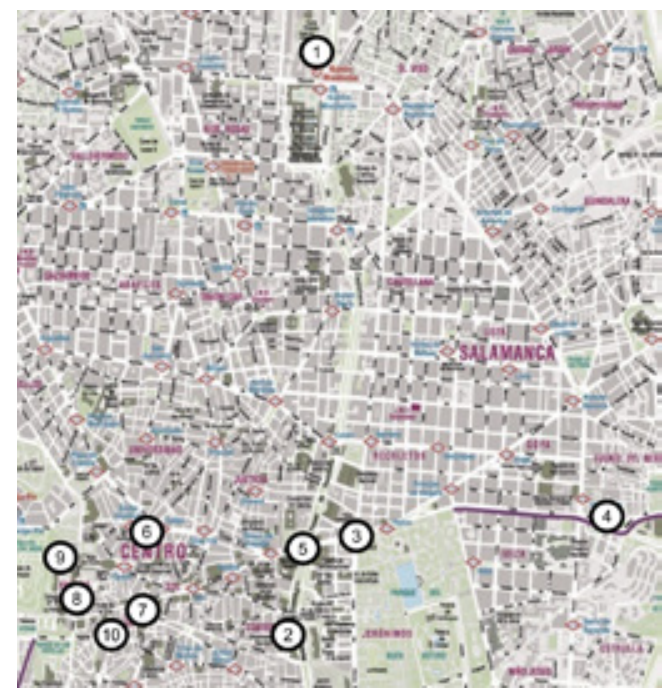

Fig. 2. Lugares de rodaje El vuelo de la paloma. Fuente: Jorge Gorostiza

medio que elige la protagonista para huir de la capital y de su matrimonio.

Los planos aéreos antes mencionados siempre se desarrollan de día, pero además se han usado otros donde va amaneciendo, como al principio de El disputado voto del señor Cayo (Antonio Giménez-Rico, 1986) en el que se muestra el tejido urbano sin enseñar monumentos, ni edificios singulares, hasta llegar al Congreso de los Diputados, en cuyo interior se inicia su argumento.

También se ve el amanecer en Madrid en los planos iniciales de El vuelo de la paloma (José Luis García Sánchez, 1989) que comienza viéndose la Torre Picasso en la Castellana, pasando por el edificio de sindicatos en el Paseo del Prado, Puerta de Alcalá sobre la que se inserta el título de la película, Torrespaña conocida como "El pirulí", Plaza de Cibeles, Puerta del Sol, Plaza Mayor, Viaducto, Palacio Real, y por último, la Plaza del Conde de Barajas donde se desarrolla el argumento de la película, la intención también es ir mostrando monumentos y edificios conocidos, sin un recorrido lógico (fig. 2), ya que la última plaza mencionada está más lejos del Palacio Real y el Viaducto que de la Plaza Mayor.

Como puede comprobarse (tab. 1), la visión de monumentos madrileños se repite y dos de ellos, la Puerta de Alcalá y el Palacio Real, ya habían 


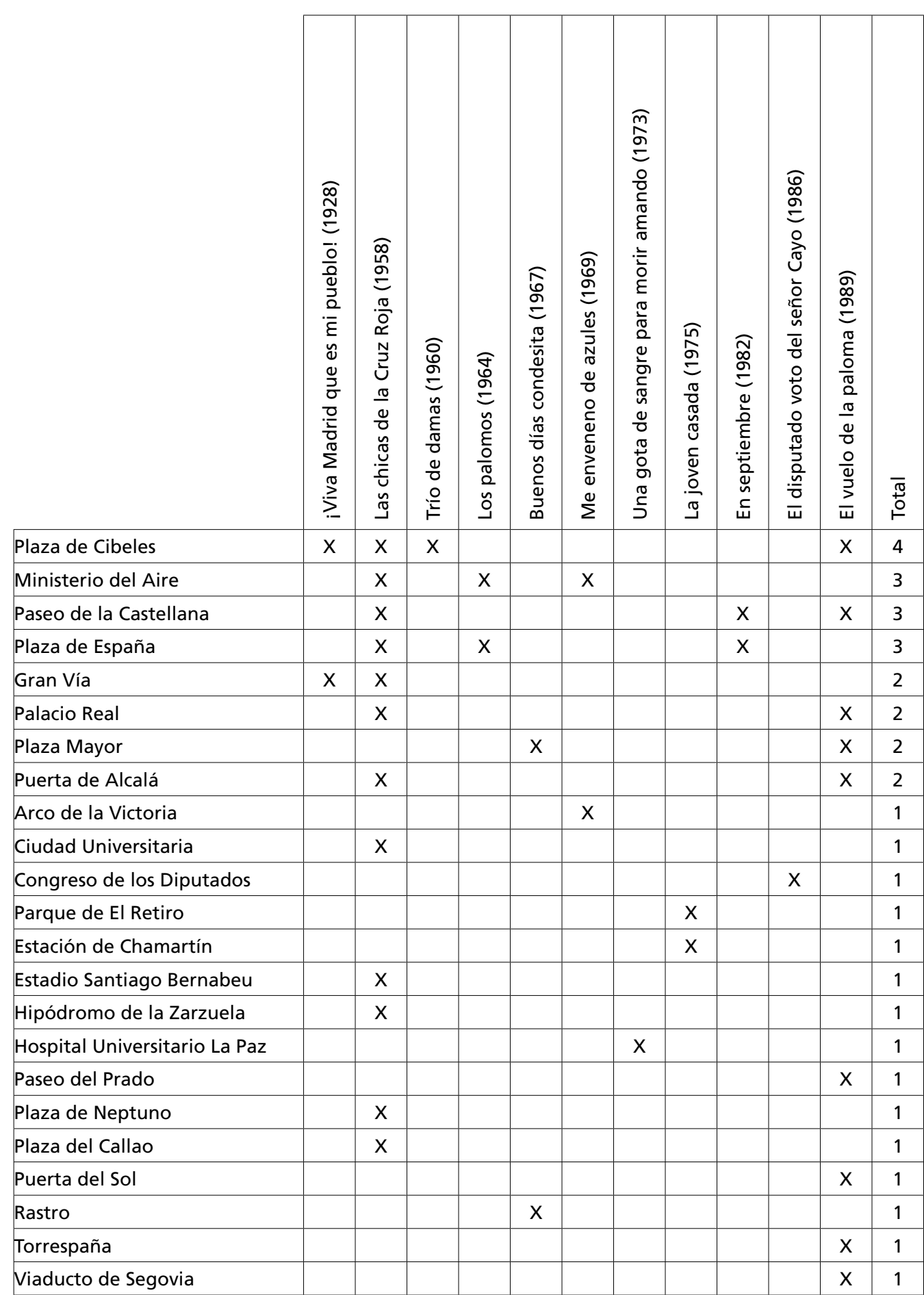


sido reproducidos desde el aire en dos grabados hechos por Alfred Guesdon en 1852, según se ha supuesto, gracias a ascender en un globo cautivo, el primero desde el Sur hacia el Norte y el segundo desde el oeste al este situándose aproximadamente en la vertical del Manzanares. Esta repetición de lugares de la capital, también se produce en otras películas en planos iniciales rodados desde el terreno y son los monumentos icónicos que representan a la ciudad en otros medios.

\section{Otra mirada}

Antes se mencionaba a André Prothin, quien también se refirió al punto de vista: «es mejor no tomar vistas demasiado verticales», porque los «monumentos desaparecen totalmente en el conjunto si pasas por encima de ellos. Hasta el punto que no pude reconocer el emplazamiento de la Catedral de Reims la primera vez que volé sobre ella, porque el piloto me había traído justo sobre su eje, y solo cuando vimos que estábamos casi sobre el lugar, me di cuenta que nos encontramos por encima del objeto de nuestro recorrido. Luego me incliné sobre las alas y distinguí el monumento que estaba buscando, y me parecieron dos grandes mesas redondas de comedor y otra larga; estábamos por encima de las dos torres y la nave ${ }^{23}$, se ha de aprender a mirar desde el aire, ya que si no se tiene ese conocimiento, los monumentos pueden asimilarse a las formas más reconocibles de objetos cotidianos.

Hoy en día sería difícil que a alguien le ocurriera lo mismo que a Prothin, porque las miradas están entrenadas en la visión cenital, gracias a los populares y ya imprescindibles, programas informáticos para visualizar cartografía, como Bing Maps, Flash Earth, Google Earth, Google Maps, MapQuest, OpenStreetMap, OpenLayers y Yahoo Maps. La mayoría de ellos relacionados con el cine, ya que como explica Teresa Castro: "Lo que llama la atención de Google Earth son sus características "cinematográficas", ilustradas por la fluidez de los movimientos aéreos que permiten al usuario navegar por el espacio-tiempo, o por la posibilidad de desarrollar movimientos en profundidad en la imagen, ya sea a través del "zoom in" o del "zoom out". Mejoradas con cada versión del software, estas funcionalidades descubren la dimensión cinética de la cartografía y la comprensión espacial que facilita» ${ }^{24}$ además esta autora advierte sobre los peligros de estos programas: "Google Earth está asociado con una fantasía de dominación panóptica en todo el planeta. Es difícil no mencionar este aspecto cuando la aplicación afirma haber fotografiado toda la superficie de la Tierra, facilitando el acceso inmediato (al menos en teoría) a cualquier punto » ${ }^{25}$. Es evidente el interés por ver, conocer y controlar de los estados, recuérdese que en sus inicios Google Earth fue financiado por la CIA.

En cuanto a los videojuegos, el tipo de plano vertical sobre el terreno, se ha empleado en muchos de ellos y es conocido en inglés como Topdown perspective (Perspectiva de arriba hacia abajo), además de por Bird's-eye view (Vista de pájaro), Overworld (Sobre el Mundo), Godview (Vista de Dios), Overhead view (Visión sobre la cabeza) y Helicopter view (Visión de helicóptero), demostrando este último como se sigue asociando la forma de mirar desde arriba a un artefacto volador.

Hoy en día, el cine y en general las imágenes en movimiento, muestran cada vez más planos desde el aire, las tecnologías de vigilancia como las empleadas a través de satélites y, sobre todo, drones, hacen posible una visión casi perfecta de toda la superficie de la tierra, llegando incluso a abusar en muchas películas de las imágenes tomadas desde estos últimos artefactos. Estos aparatos de vuelo dirigidos desde tierra se emplearon ya en la Primera Guerra Mundial y en la actualidad se han popularizado hasta extremos asombrosos, su nombre viene de la palabra inglesa drone, que significa abeja macho o zángano, un gandul en nuestro idioma, y siguen dividiéndose en dos tipos: aviones y helicópteros, según sus movimientos, pero tienen la novedad de su tamaño reducido y la ausencia de piloto, por lo que la implicación del ser humano con lo representado es aún más lejana que cuando se emplean aeronaves tripuladas.

Los paisajes urbanos que se muestran en el cine han variado al haberse globalizado las ciudades un ejemplo es Up in the Air (Up in the Air, Jason Reitman, 2009) en la que hay unos rótulos indicando a qué ciudad va llegar el protagonista 
y lo que se ve detrás es igual en todas ellas distinguiéndose solo por su nombre.

Las nuevas formas de mirar también han afectado en la construcción del espacio escenográfico cinematográfico se ha realizado con varios procedimientos, entre los fílmicos está el montaje, que he dividido en tres tipos: Limitado, Difuso y Esquemático ${ }^{26}$, este último se ha producido en los últimos años, es una mezcla de los dos anteriores y se suele realizar gracias a técnicas digitales, en este espacio gráfico se mezclan y superponen muchas imágenes que a veces no suceden en el mismo tiempo, ni en el mismo lugar; este nuevo instrumento da más información, rompiendo el encuadre tradicional y permite nuevas posibilidades narrativas y espaciales. Los esquemas empleados son muy variados y recuerdan a programas de ordenador, como los de presentaciones, pero los que interesan aquí son aquellos similares a programas para representar ciudades como Google Maps, un ejemplo es Asalto al tren Pelham 123 (The Taking of Pelham 12 3, Tony Scott, 2009) en la que cuando se ha de transportar el dinero del rescate de un lugar a otro de Manhattan, en la pantalla se muestran sus situaciones reales, con textos indicando los nombres de las calles e imágenes muy parecidas a las usadas en esos programas; otro ejemplo es Crank: Veneno en la sangre) y su secuela Crank: Alto voltaje (Crank 2: High Voltage) ambas dirigidas por Mark Nevedine y Brian Taylor en 2006 y 2009, en las que para indicar los enloquecidos trayectos del protagonista, se utilizan directamente imágenes de Google, con sus teclas de movimiento y ampliación, incluso apareciendo en sus ángulos inferiores derechos el anagrama de esa empresa.

Volviendo a Le Corbusier, el punto de vista desde el aire justifica su frase: «el avión acusa a la ciudad $\${ }^{27}$, concretando la razón de esta denuncia: «El avión observa la ciudad con su ojo de águila.
Observa Londres, París, Berlín, Nueva York, Barcelona, Argel, Sao Paulo. ¡Ay, qué lastimoso elenco! El aeroplano revela un hecho incuestionable: los hombres que han construido las ciudades no buscaban el placer, la satisfacción o la felicidad, jsino hacer dinero! »28 y continúa: «El aeroplano examina, actúa rápidamente, contempla velozmente sin cansarse y eso no es todo: llega al corazón de la cruel realidad. Con su ojo de águila penetra en la miseria de las ciudades ${ }^{29}$. La denuncia de Le Corbusier, sigue estando vigente, incluso cuando se han seguido sus planteamientos urbanísticos, el actual conocimiento de la realidad urbana, gracias a nuevas herramientas, debería servir no solo para formular una acusación contundente, sino además para que se mejoren los entornos en los que ha de vivir el ser humano en este nuevo siglo.

En su momento la vista de la ciudad desde el aire significó una novedad crucial que sirvió para analizarla, criticarla e intentar modificarla, en la actualidad ya no hace falta observar las ciudades desde una aeronave en directo o en diferido proyectadas sobre una pantalla cinematográfica, porque cualquiera puede ver cómo son las poblaciones de todo el mundo, desde cualquier lugar sentado delante del monitor de su ordenador. Esta posibilidad sirve para comprobar fácilmente que esta forma de mirar conlleva una transformación de lo observado, incluso físicamente en la realidad.

La representación en movimiento y desde el aire de las ciudades implica un nuevo modo de pensar y experimentar el paisaje urbano, diferente al cotidiano desde el terreno, un conocimiento que además ha provocado un cambio significativo en la forma de ser de esos espectadores transeúntes en que se han convertido la mayoría de los seres humanos. 


\section{NOTAS}

1 Le Corbusier, Aircraft (Madrid; Abada, 2003), 86.

2 Filippo Tommaso Marinetti, "Manifiesto técnico de la literatura futurista," in Manifiestos futuristas (Barcelona: Ediciones del Cotal, 1978), 163.

3 Juan José Lahuerta, "Ciudad / Avión," in Ciudades sin nombre (Madrid: Comunidad de Madrid, 1998), 15

4 Juan José Lahuerta, "Ciudad / Avión," in Ciudades sin nombre (Madrid: Comunidad de Madrid, 1998), 15.

${ }^{5}$ Le Corbusier, Hacia una arquitectura (Buenos Aires: Poseidón, 1978) 85.

${ }^{6}$ Le Corbusier, Hacia una arquitectura (Buenos Aires: Poseidón, 1978) XXXI.

7 Le Corbusier, Aircraft (Madrid; Abada, 2003), 73.

${ }^{8}$ Le Corbusier, Aircraft (Madrid; Abada, 2003), 13.

${ }^{9}$ Edgar Morin, El cine o el hombre imaginario (Barcelona: Paidós, 2001), 13.

${ }^{10}$ Citado por Paul Virilio, Guerre et cinéma I. Logistique de la perception. Paris: Cahiers du Cinéma., 1991), 15.

${ }^{11}$ Jorge Gorostiza. 2015. "La pantalla, límite entre realidad y ficción." Anales de la Real Academia Canaria de Bellas Artes, no. 8: 52.

${ }^{12}$ André Prothin. 1911. "La Cinématographie en Aéroplane." Cine-Journal 4, no. 167 (4 november): 8.
${ }^{13}$ Anónimo. 1920. "Moreno Photographing Full Sequence from Baby Blimp." Moving Picture World 46, no 6 (9 october): 827.

${ }^{14}$ Teresa Castro. "Cinematic Cartographies of Urban Space and the Descriptive Spectacle of Aerial Views (1898-1948)." in Cinematic Urban Geographies, edited by François Penz and Richard Koeck (New York: Palgrave Macmillan, 2017) 48.

${ }^{15}$ Teresa Castro. "Cinematic Cartographies of Urban Space and the Descriptive Spectacle of Aerial Views (1898-1948)." in Cinematic Urban Geographies, edited by François Penz and Richard Koeck (New York: Palgrave Macmillan, 2017) 48.

${ }^{16}$ Siegfried Krakacuer, De Caligari a Hitler: Historia psicológica del cine alemán (Barcelona: Paidós, 1985), 273.

${ }^{17}$ Mark Dorrian. 2007. "The aerial view: notes for a cultural history,." in Strates: Matériaux pour la recherche en sciences sociales, no. 13: 3.

${ }^{18}$ Sergei M. Eisenstein, Hacia una teoría del montaje, Vol. 1 (Barcelona: Paidós, 2001) 151,

${ }^{19}$ Mark Dorrian. 2007. "The aerial view: notes for a cultural history," in Strates: Matériaux pour la recherce en sciences sociales, no. 13: 8 .

${ }^{20}$ Philippe Dubois, "Le regard vertical: ou les transformations du paysage," in Les paysages du cinéma, edited by Jean Mottet (Seyssel: Champ Vallon, 1999), 25.

${ }^{21}$ Jorge Gorostiza, 2019. "Desde el cielo y en descenso hasta el monumento: Ciudades en principios de películas." Bitácora Arquitectura, no. 40: 85.

${ }^{22}$ Este plano se parece al inicial de Casablanca (Casablanca, Michael Curtiz, 1942), en el que también hay una visión de todo un globo terráqueo asombrosamente inmerso en nubes.

${ }^{23}$ André Prothin. 1911. "La Cinématographie en Aéroplane." Cine-Journal 4, no. 167, (4 november): 8.

${ }^{24}$ Teresa Castro. La pensée cartographique des images (Lyon: Aléas, 2008), 237.

${ }^{25}$ Teresa Castro. La pensée cartographique des images (Lyon: Aléas, 2008), 237.

${ }^{26}$ Jorge Gorostiza. 2016. "La construcción de la ficción: Espacio arquitectónico - espacio cinematográfico." PhD diss., Escuela de Arquitectura de la Universidad Politécnica de Madrid. 165.

${ }^{27}$ Le Corbusier, Aircraft (Madrid; Abada, 2003), 76.

${ }^{28}$ Le Corbusier, Aircraft (Madrid; Abada, 2003), 11.

${ }^{29}$ Le Corbusier, Aircraft (Madrid; Abada, 2003), 12. 


\section{REFERENCIAS}

Anónimo. 1920. "Moreno Photographing Full Sequence from Baby Blimp." Moving Picture World 46, no. 6 (October 9): 827.

Castro, Teresa. 2008. La pensée cartographique des images. Lyon: Aléas.

Castro, Teresa. 2017. "Cinematic Cartographies of Urban Space and the Descriptive Spectacle of Aerial Views (1898-1948)." In Cinematic Urban Geographies, edited by François Penz y Richard Koeck, 47-63. Nueva York: Palgrave Macmillan. https://doi.org/10.1057/978-1137-46084-4_3

Le Corbusier. 1978. Hacia una arquitectura. Buenos Aires: Poseidón.

Le Corbusier. 2003. Aircraft. Madrid: Abada.

Dorrian, Mark. 2007. "The aerial view: notes for a cultural history." Strates: Matériaux pour la recherce en sciences sociales 13: 1-17.

Dubois, Philippe. 1999. "Le regard vertical: ou les transformations du paysage." In Les paysages du cinéma, edited by Jean Mottet, 24-44. Seyssel: Champ Vallon.

Eisenstein, Sergei M. 2001. Hacia una teoría del montaje, Vol. 1. Barcelona: Paidós

Gorostiza, Jorge. 2015. "La pantalla, límite entre realidad y ficción." Anales de la Real Academia Canaria de Bellas Artes 8: 51-64.
Gorostiza, Jorge. 2016. "La construcción de la ficción: Espacio arquitectónico - espacio cinematográfico." PhD diss., Escuela de Arquitectura de la Universidad Politécnica de Madrid.

Gorostiza, Jorge. 2019. “Desde el cielo y en descenso hasta el monumento: Ciudades en principios de películas." Bitácora Arquitectura 40: 78-85. https://doi.org/10.22201/ fa.14058901p.2019.40.69441

Lahuerta, Juan José. 1998. "Ciudad / Avión." In Ciudades sin nombre, 11-16. Madrid: Comunidad de Madrid.

Krakacuer, Siegfried. 1985. De Caligari a Hitler: Historia psicológica del cine alemán. Barcelona: Paidós.

Marinetti, Filippo Tommaso. 1978. "Manifiesto técnico de la literatura futurista." In Manifiestos futuristas, 156-166. Barcelona: Ediciones del Cotal.

Morin, Edgar. 2001. El cine o el hombre imaginario. Barcelona: Paidós.

Prothin, André. 1911. "La Cinématographie en Aéroplane." Cine-Journal , no. 167 (November 4): 5-8.

Virilio, Paul, 1991. Guerre et cinéma I. Logistique de la perception. Paris: Cahiers du Cinéma. 